\title{
Climate-driven interannual ice mass evolution in Greenland
}

\author{
I. Bergmann ${ }^{\mathrm{a}}$, G. Ramillien ${ }^{\mathrm{b}}$, F. Frappart ${ }^{\mathrm{b}}$ \\ ${ }^{a}$ Helmholtz-Centre Potsdam, GFZ German Research Centre for Geosciences, Potsdam, Germany \\ ${ }^{b}$ Université de Toulouse, UPS, OMP, GET, Toulouse, France
}

\begin{abstract}
We re-evaluate the Greenland mass balance for the recent period using low-pass Independent Component Analysis (ICA) post-processing of the Level-2 GRACE data (2002-2010) from different official providers (UTCSR, JPL, GFZ) and confirm the present important ice mass loss in the range of -70 and $-90 \mathrm{Gt} / \mathrm{y}$ of this ice sheet, due to negative contributions of the glaciers on the east coast. We highlight the high interannual variability of mass variations of the Greenland Ice Sheet (GrIS), especially the recent deceleration of ice loss in 2009-2010, once seasonal cycles are robustly removed by Seasonal Trend Loess (STL) decomposition. Interannual variability leads to varying trend estimates depending on the considered time span. Correction of post-glacial rebound effects on ice mass trend estimates represents no more than $8 \mathrm{Gt} / \mathrm{y}$ over the whole ice sheet. We also investigate possible climatic causes that can explain these ice mass interannual variations, as strong correlations between GRACE-based mass balance and atmosphere/ocean parallels are established: (1) changes in snow accumulation, and (2) the influence of inputs of warm ocean water that periodically accelerate the calving of glaciers in coastal regions and, feed-back effects of coastal water cooling by fresh currents from glaciers melting. These results suggest that the Greenland mass balance is driven by coastal sea surface temperature at time scales shorter than accumulation.
\end{abstract}

Keywords: ice sheets, mass balance estimates, Greenland, GRACE

Email addresses: Inga. Bergmann@gfz-potsdam. de (I. Bergmann), guillaume.ramillien@get.obs-mip.fr(G. Ramillien),

frederic.frapparteget.obs-mip.fr(F. Frappart) 


\section{Introduction}

The mass balance of the Greenland Ice Sheet (GrIS), and its contribution to sea level rise, are of high interest in the context of global warming. According to the latest IPCC report (2007), melting of the whole GrIS would contribute nearly $7 \mathrm{~m}$ to sea level rise. Even a less substantial mass loss would have a strong impact on sea level rise. Over the last twenty years, observations of the GrIS show an acceleration of ice mass loss caused by rapid glacier flow on the southeast and northwest coasts (see Allison et al. (2009) and Zwally et al. (2011) for reviews), in response to the recent warming affecting both the atmosphere (Box and Cohen, 2006) and sea water (Hanna et al., 2009). Nevertheless, analysis of changes in the glaciers reveals a succession of periods of mass loss acceleration and deceleration.

Since its launch in March 2002, the GRACE mission has demonstrated great potential for studying the ice sheet mass changes. The GRACE data have been increasingly used for assessing mass balance of Greenland and Antarctica. First studies revealed a significant mass loss of Greenland with an acceleration of melting starting in 2004 (Velicogna and Wahr, 2005, 2006; Chen et al., 2006; Luthcke et al., 2006; Ramillien et al., 2006). Mass loss occurred mainly on the east coast of Greenland whereas the interior of the continent exhibited a small mass increase (Luthcke et al., 2006; Wouters et al., 2008). Recent studies showed acceleration of the mass loss during 2006-2008 (Velicogna, 2009) and a deceleration during 2008-2009 (Chen et al., 2011). Nevertheless, the results obtained so far are highly dependent on the length of the GRACE time series, the chosen data set, the nature of the post-processing, and the method for computing linear trends (i.e., with or without adjusting the seasonal components). Results can vary by a factor $\sim 3$ depending on the data set (e.g. CSR, GFZ or JPL; Baur et al., 2009). From these previous GrIS mass balance estimates, linear trends were simply computed over the complete (or parts of the) period of availability of the GRACE data, assuming the ice melting to be constant in time. Only Velicogna (2009) and Rignot et al. (2011) estimated accelerations for 2004 and 2008-2009.

In this study, we re-evaluate the Greenland mass balance over a longer time span (October 2002 - July 2010), using Level-2 GRACE data from the Science Data Centre 
(UTCSR, GFZ and JPL) and different post-processing techniques (Gaussian and Independent Component Analysis-based approaches) at continental and ice field scales. We also analyze the interannual variability of the mass balance using the robust Seasonal Trend Decomposition by Loess (LOcally wEighted Scatterplot Smoothing) (STL) approach. The non-stationarity of the mass balance is then related to climate forcings from the atmosphere and the ocean through comparisons with snow depths (SD) and sea surface temperatures (SST).

\section{Data sets}

\subsection{GRACE-based water mass variations}

Since its launch in March 2002, the Gravity Recovery And Climate Experiment (GRACE) mission, consisting of a pair of co-orbiting satellites at an altitude of 400$450 \mathrm{~km}$, provides a systematic mapping of the spatio-temporal variations of the Earth's gravity field. These are estimated with an unprecedented precision of $\sim 1 \mathrm{~cm}$ in terms of geoid height (Tapley et al., 2004), or equivalently $\sim 15-20 \mathrm{~cm}$ in equivalent-water thickness when averaged in regions of 300x300 of square kilometers (Ramillien et al., 2008; Schmidt et al., 2008). The Level-2 GRACE solutions consist of monthly Stokes coefficients (i.e., normalized spherical harmonics of the geo-potential) estimated by a leastsquares adjustment of GRACE orbit measurements -especially very accurate intersatellite K-Band Range (KBR) variations- made by different official providers [GeoForschungsZentrum (GFZ) in Potsdam Germany, Center of Space Research at University of Texas (UTCSR) in Austin, TX, Jet Propulsion Laboratory (JPL) in Pasadena, CA]. In this process, the Stokes coefficients are corrected for known atmospheric and oceanic gravitational contributions (Bettadpur , 2007), so that the residuals represent non-modeled phenomena, mainly variations in land water storage, glaciers, and ice sheet mass. These Level-2 GRACE solutions are available at: ftp://podaac.jpl.nasa.gov/grace/ up to harmonic degree of 50-60 (i.e., spatial resolution of 333-400 km), and the corresponding global $1^{\circ} \times 1^{\circ}$ grids of equivalent-water heights are also downloadable. In our study, we use monthly GFZ, UTCSR and JPL solutions from 04/2002 to 07/2010. The GRACE solutions suffer from the presence of an unrealistic high-frequency noise 
appearing as north-south striping, caused by orbit resonance during the Stokes coefficient determination and aliasing with short-term oceanic and atmospheric phenomena that are not well modeled. Several post-processing methods, such as low-pass Gaussian filtering, have been proposed to solve this problem (Jekeli, 1981; Swenson and Wahr, 2002). However most of them suffer from the risk of losing signal energy in the spectrum truncation (i.e., drastic loss of spatial resolution). This also needs arbitrary tuning of required parameters (e.g., a priori level of noise, cutting spatial frequencies,...) in absence of criteria. To get rid of the noise in the L-2 GRACE solutions, we preferred to use the global ICA estimates obtained by combination of GFZ/UTCSR/JPL solutions, to isolate statistically independent components of the observed gravity field, in particular the continental water storage contribution that we compared with continental water storage estimated from classical Gaussian-filtered solutions.

\subsection{ICA solutions}

A post-processing method based on ICA (Comon , 1994; De Lathauwer et al. , 2000) was applied to the Level-2 GRACE solutions prefiltered with Gaussian filters of $400 \mathrm{~km}$ and $500 \mathrm{~km}$ of radius. This so-called blind source separation (BSS) approach does not require a priori information, except the assumption of statistical independence of the elementary sources that compose the total measured signals. Taking into account the consideration that the GRACE Level-2 products from CSR, GFZ and JPL are different observations of the same monthly gravity anomaly, and that the land hydrology and the north-south stripes are the independent sources.

Assuming that the observations $y$ collected from $N$ sensors are the combination of $P$ $(N \geq P)$ independent sources represented by the source vector $x$, they can be written as a linear statistical model:

$$
y=M x
$$

where $M$ is the mixing matrix whose elements $m_{i j}(1 \leq i \leq N, 1 \leq j \leq P)$ indicate to what extent the jth source contributes to the ith observation. The columns $\left\{m_{j}\right\}$ are the mixing vectors. ICA aims at estimating the mixing matrix $M$ and/or the corresponding realizations of the source vector $x$, only knowing the realizations of the 
observation vector $y$, under the following assumptions: i) the mixing vectors are linearly independent, and ii) the sources are statistically independent. The contributors to the observed gravity field are forced to be uncorrelated, numerically only considering completely objective constraints. The efficiency of ICA to separate gravity signals and noise from combined GRACE solutions has previously been demonstrated on Level-2 solutions over land (Frappart et al., 2010, 2011). Series of ICA-estimated global maps of continental and ice caps mass changes, computed over 08/2002-07/2010, are used in this study to estimate the mass balance of Greenland.

\subsection{ECMWF Snow depth data}

We used the daily snow depth grids from the European Centre for Medium-Range Weather Forecasts (ECMWF) ERA-interim reanalysis with a horizontal resolution of $1.5^{\circ} \times 1.5^{\circ}$ (http://data-portal.ecmwf.int/data/d/interim_daily/; Dee et al. , 2011). These grids were estimated from the improved snow scheme of the Hydrology Tiled ECMWF Scheme of Surface Exchanges over Land (HTESSEL) land surface model. It includes a new parametrization of snow density, incorporating a liquid water reservoir, and revised formulations for the sub grid snow cover fraction and snow albedo (Dutra et al., 2010). The daily grids of snow depth were averaged monthly over the period April 2002 to July 2010, for comparisons with the total water storage derived from GRACE.

\subsection{NOAA Sea Surface Temperature}

In this study, we used the National Oceanic and Atmospheric Administration (NOAA) Optimum Interpolation Sea Surface Temperature Analysis Version 2, available at http://www.esrl.noaa.gov/psd/. They consist of weekly grids produced by optimal interpolation (Reynolds and Smith, 1994). Monthly solutions are then estimated by linear interpolation of weekly fields to daily fields, and averaging the daily values over a month. The monthly fields have a resolution of $1^{\circ} \times 1^{\circ}$ on a global half degree grid. Data from April 2002 to July 2010 are used in this study. 


$$
\Delta \sigma(\phi, \lambda, t)=\frac{a_{e} \rho_{e}}{3 \rho_{w}} \sum_{l=2}^{\infty} \sum_{m=0}^{l} \frac{2 l+1}{1+k_{l}} P_{l m}(\sin \phi)\left(\Delta C_{l m} \cos m \lambda+\Delta S_{l m} \sin m \lambda\right)
$$

\section{Methodology}

\subsection{Mass anomalies from GRACE data}

The monthly Stokes coefficients of the GRACE solutions are used to estimate mass anomalies by spherical harmonic expansion (Wahr et al., 1998). After removing a temporal average, monthly maps of surface mass density anomalies $(\Delta \sigma)$ can be computed as:

where $a_{e}$ is the semi major axis, $\rho_{e}$ the average density of the earth $\left(5517 \mathrm{~kg} / \mathrm{m}^{3}\right)$, $\rho_{w}$ the density of water $\left(1000 \mathrm{~kg} / \mathrm{m}^{3}\right), k_{l}$ are the elastic Love numbers of degree $l$, $P_{l m}$ are the normalized associated Legendre Polynomials of degree $l$ and order $m, \phi$ is the geographical latitude, $\lambda$ the geographical longitude, $t$ the time and $\left(\Delta C_{l m}, \Delta S_{l m}\right)$ are the fully normalized dimensionless spherical harmonic (Stokes) coefficients given by GRACE. The $\Delta \sigma$ are given in meters of equivalent water height. The spherical harmonic expansion has been performed up to degree and order 60 which leads to a spatial grid resolution of $\sim 333 \mathrm{~km}$.

To remove the noise due to aliasing of short-term phenomena (inducing north-south stripes) the solutions have to be filtered. In this work a Gaussian filter with a half width radius of $400 \mathrm{~km}$ and $500 \mathrm{~km}$ was used. As mentioned in section 2.2, the Gaussian filtered solutions are further destriped by applying of the ICA method.

Mass variations $\Delta \sigma$ are computed at each time step and grid point, and have been further averaged in the boundaries of the GrIS and subregions.

\subsection{Correction of the Post-Glacial Rebound}

Over Canada and northwestern Europe, the last deglaciations ( 20 k-years ago) of thick ice sheets caused rapid deloadings of ice mass. Because of its viscoelastic behavior, i.e. Post Glacial Rebound (PGR), the Earth's mantle is still continuing a non negligible isostatic re-adjustment (Peltier, 2004). As a consequence of this longterm deformation, the Earth's surface and gravity field are still affected by PGR at 
linear rates. For example, in the South of Hudson Bay in Canada, the uplift of the surface measured at GPS sites reaches $1.1 \mathrm{~cm} / \mathrm{yr}$ (Sella et al., 2007). Knowledge of the deglaciation history and the Earth's mantle viscosity remains limited to uncertainties in PGR modeling. However, according to independent models, PGR geographicallyaveraged over Greenland shows negative trends weaker than $10 \mathrm{Gt} / \mathrm{yr}$, and is considered by some authors to be weak compared to ice mass loss. Using different PGR models, comparable PGR estimates, from 7 or $8 \mathrm{Gt} / \mathrm{yr}$ were found (Velicogna and Wahr, 2006; Velicogna, 2009) considering the ICE-5G model of Peltier (2004), and up to $9 \mathrm{Gt} / \mathrm{y}$ (Ramillien et al., 2006) using the IJ-2005 model developed by Ivins and James (2005). As it is available at the GRACE Tellus website (http://grace.jpl.nasa.gov/data/pgr), we consider the Paulson et al. (2007) model based on the ICE-5G ice model and a tuning of mantle viscosity contrasts and crust thickness. The $1^{\circ} \times 1^{\circ}$ grid of PGR trend has been downloaded from this website, and the Stokes coefficients of the PGR have been converted into rates of surface mass change and expressed in mm of water height per year. Degree-one terms were omitted as they are not included in the GRACE solutions. The results were smoothed using a Gaussian averaging function of 400 and $500 \mathrm{~km}$ radius. Over the whole of Greenland, we found a PGR trend close to $-8 \mathrm{Gt} / \mathrm{yr}$, representing -4 $\mathrm{mm} / \mathrm{yr}$ of equivalent-water height. For each time step the modeled PGR contribution has been removed from the filtered GRACE mass anomalies.

When interpreting the PGR-corrected Greenland mass balance, we keep in mind that the PGR model uncertainty can represent an important source of error.

\subsection{Seasonal-Trend Decomposition by Loess (STL) Method}

The STL method, based on locally weighted regression (Cleveland et al., 1990), is a robust and computationally efficient approach commonly used to decompose time series into trend $\left(T_{v}\right)$, seasonal $\left(S_{v}\right)$, and residual $\left(R_{v}\right)$ components:

$$
Y_{v}=T_{v}+S_{v}+R_{v}
$$

STL is an iterative method consisting of two recursive procedures, one nested within the other, called the inner and the outer loops. The trend and seasonal estimates are 
progressively refined in the inner loop in each iteration. After one complete run of the inner loop, robustness weights are computed in the outer loop. These weights are used in the next run of the inner loop to reduce the influence of outliers in the trend and seasonal signal. The local weights $\vartheta_{v}$ of the values depend on the time steps to the observed time in a chosen window with size $q$. A polynomial with power $d$ is fitted to the weighted data.

The inner loop contains six steps. In the first step of the kth run of the inner loop, the time series $Y_{v}$ is detrended with $T_{v}^{k}$ :

$$
Y_{v}^{\text {detrend }}=Y_{v}-T_{v}^{k}
$$

In the next step (step 5), the original time series is reduced by the seasonal signal:

$$
Y_{v}^{\text {deseason }}=Y_{v}-S_{v}^{k+1}
$$

${ }_{183}$ In the last step (step 6) the reduced time serie from step 5 is smoothed by locally 184 weighted regression with $d=1$ to receive the updated trend signal $T_{v}^{k+1}$. signal $R_{v}$ :

$$
R_{v}=Y_{v}-T_{v}^{k+1}-S_{v}^{k+1}
$$


For each time step a robustness weight $\rho_{v}$ is determined. Outliers will have a very small or zero weight. In the next run of the inner loop the robust weight will be multiplied to the weights $\vartheta_{v}$ in the locally weighted regression in step 2 and 6.

The Fortran-Code for the STL-Method has been provided at the following webpage: http://www.stat.purdue.edu/wsc/localfitsoft.html. For an easy start into the method the function stlez. $f$ has been used. In this function just the main necessary parameters have to be entered by the user:

1) The number of observations $n_{p}$ which are included in each period. We have time series with monthly resolution and an annual signal, choosing $n_{p}=12$.

2) The number of iterations of the inner $\left(n_{i}\right)$ and outer $\left(n_{o}\right)$ loop. Because, that the convergence of estimating the different components of the signal is very fast, $n_{i}$ can be set to 1 . If a robust estimation of the signals is preferred, the determination of the robust weight in the outer loop is done until the convergence criteria is reached, or with a maximum of $n_{o}=15$.

3) In step 2 the estimated seasonal signal is smoothed by Loess with the parameters $d=1$ and $q=n_{s}$. The seasonal signal becomes smoother with increasing $n_{s}$. At minimum, $n_{s}$ has to be odd and greater than 6 . Due to this fact $n_{s}=7$ has been chosen. 4) In step 3 the smoothing with Loess, with parameter $d=1$ and $q=n_{l}$, is applied. The weight factor $n_{l}$ has to been chosen as the least odd number equal to $n_{p}$. In this case with $n_{p}=12$, then $n_{l}=13$.

5) In the last step (step 6), the trend signal is smoothed with Loess with $d=1$ and $q=n_{t}$. The parameter $n_{t}$ should be the least odd integer value greater or equal to

$$
n_{t} \geq \frac{1.5 * n_{p}}{1-\frac{1.5}{n_{s}}}
$$

With the above given values for the parameters $n_{p}$ and $n_{s}$, then $n_{t}=21$.

\section{Results and Discussion}

\subsection{Re-evaluation of the recent Greenland mass change}

Gaussian-filtered and smoothed ICA solutions were averaged over Greenland by simply using a geographical mask over the period 2002-2010. Figure 1 presents the six 
mean ice fields composing the Greenland ice sheet (acc. to Luthcke et al., 2006). The corresponding ICA-based time series were corrected for the seasonal signal by applying the STL decomposition (explained in paragraph 3.3). Velicogna (2009) proposed an additional filtering to cancel the long term and periodic contributions in the GRACE data, based on the least-square adjustment of annual, semi-annual, trend and constant terms using 13-month running windows. Instead of fitting empirical periodic variations, we preferred to apply the more robust STL method for extracting the long-term signals. To illustrate the benefit of using the STL decomposition, Fig. 2 compares the Greenland mass balance based on the method developed here (STL, ICA), to classical Gaussian filtering. The decreasing behavior of these curves confirms the mass depletion of this ice sheet due to important melting during the GRACE period. Moreover, these GRACE-derived time series also contain annual and sub-annual signals that need to be isolated in order to extract the interannual ice mass variations. Differences between ICA and Gaussian filtered estimates are not always correlated for wavelengths less than 1 year, and they can reach $100 \mathrm{~mm}$ of equivalent-water height. These shortterm differences can be accounted for a reduction of the residual noise by ICA after the Gaussian low-pass filtering. Fig. $2 b$ presents the STL-smoothed time series containing the interannual variations of GrIS ice mass, which are not a simple straight line, suggesting that GrIS ice mass loss cannot be represented by a constant slope. In the next sections, we attempt to explain the presence of such interannual variations by establishing correlations in time with climate forcings.

Depending on the chosen period and time length, the linear trends computed along the time series are not constant. For example, there are obvious accelerations of ice melting (Velicogna and Wahr, 2006; Velicogna, 2009), and a relative deceleration in 2009-2010, in agreement with the results found by Rignot et al. (2011) for Greenland during the last years. The change of the GrIS mass balance for the complete GRACE period (i.e., between 2003 and 2010) still exhibits a huge mass loss, even before the constant negative rate of $\sim-8 \mathrm{Gt} / \mathrm{yr}$ for PGR is removed from the linear trend estimates. The amplitude of these trend estimates clearly varies with the GRACE solution provider (i.e., CSR, GFZ, JPL) and the post-processing (i.e., ICA or only Gaussian low-pass filtering). In terms of sensitivity relative to the GRACE solution source, the lowest values 
are systematically obtained with the JPL solutions. This is probably due to some specific pre-processings of the GRACE measurements made by this provider. Low linear trends were already found by Baur et al. (2009) using JPL solutions over Greenland while CSR solutions give values twice as large (see Table 1).

Use of ICA instead of Gaussian filtering makes the GrIS ice mass time series smoother. As a consequence ICA-based linear trends are smaller. In the case of Gaussian low-pass filtering, the larger the cutting wavelength the lower the trend estimate. By using the 400-km Gaussian-filtered solutions, the 2003-2010 rate ranges from -35 $\pm 2 \mathrm{Gt} / \mathrm{yr}$ for JPL to $-89 \pm 2 \mathrm{Gt} / \mathrm{yr}$ for CSR. With the $500-\mathrm{km}$ ICA solutions, this rate varies from -56 $\pm 2 \mathrm{Gt} / \mathrm{yr}$ for JPL to $-74 \pm 3 \mathrm{Gt} / \mathrm{yr}$ for CSR. Whatever type of post-processing is used, using the JPL solutions yields to the lowest linear trend estimates, with magnitudes $<60 \mathrm{Gt} / \mathrm{yr}$ for ICA processing, and $<40 \mathrm{Gt} / \mathrm{yr}$ for the Gaussian filter, once correcting from the PGR effects.

Comparison with PGR-corrected GrIS ice mass loss estimates from previous studies leads to important differences (see Table 1 and Figure 3). These differences can be explained by the different time spans considered in this study and the high interannual variability of the GrIS ice mass change, as previously shown on the Fig.2a-b. We checked this by computing trends over different time spans. As shown in Figure 3, trend estimates are highly dependent on both the considered time span and the methodology used. For instance, we obtained STL-base (and linear) trends of respectively -96.5 (-100.3), -78.3(-74.7), -106.8 (-115.2) Gt/yr for the periods 04/2002-11/2009, 04/2002-03/2005, 04/2005-11/2009, using CSR solutions Gaussian filtered with a radius of $400 \mathrm{~km}$, whereas Chen et al. (2011) found linear trends of respectively -219 , $-144,-248 \mathrm{Gt} / \mathrm{yr}$ over the same time periods using CSR solutions, after low-pass Gaussian filtering using a radius of $300 \mathrm{~km}$ and correcting of leakage and biases of GRACE. Our trend estimates using Gaussian-filtered solutions are slightly lower (i.e., around $-80 \mathrm{Gt} / \mathrm{yr}$ ), but remain consistent in amplitude with the results of previous works (e.g., Ramillien et al. (2006) obtained -109 Gt/yr considering the period 07/2003 - 03/2005). The Gaussian filter-based estimates often differ by more than a factor 2, since Wouters et al. (2008) found -171 Gt/yr for the period 03/2003 -01/2008, Baur et al. (2009) obtained $-222 \pm 13,-178 \pm 22,-88 \pm 21 \mathrm{Gt} / \mathrm{yr}$ for the period $08 / 2002-07 / 2008$ considering 
the CSR, GFZ, and JPL solutions, and Chen et al. (2011) proposed a value of -219 Gt/yr for 04/2002-11/2009. Velicogna and Wahr (2006) found an extreme value of $240 \mathrm{Gt} / \mathrm{yr}$ considering a shorter period. In fact, these latter authors proposed to multiply artificially their GrIS ice mass estimate by a scaling factor of $\sim 2$, to compensate the leakage effects over Greenland (i.e., loss of signal energy due to the spherical harmonics truncation at degree 50-60). The large value of this scaling factor over Greenland was empirically estimated from global hydrology model simulations (see Velicogna and Wahr (2006), p.331). It explains mostly the difference of previous studies and our Gaussian filter-based estimates. The lowest estimates are found by using the ICAbased time series $(<70 \mathrm{Gt} / \mathrm{y})$. ICA reduces the magnitude of the North-South stripes that are not correlated with continental hydrology signals (Frappart et al., 2010, 2011). The choice of the cutting wavelength before ICA separation has strong consequences on the level of noise in the pre-filtered solutions, and thus on the amplitude of the linear trend estimates. When the noise in the pre-filtered solutions increases, the standard deviations of the linear trend estimates do the same. In other words, a large amount of error in the trend estimate may come from the dispersion of the starting points on which a straight line is fitted.

Consequently, the noise-free ICA-based solution corresponds to a sea level contribution of $0.19 \mathrm{~mm} / \mathrm{yr}$. This is less than the one proposed by previous studies, in particular by Velicogna and Wahr (2006) $(0.5 \pm 0.1 \mathrm{~mm} / \mathrm{yr})$ for the same period $2002-2006$. The most important point is that this GrIS contribution varies from year to year and thus cannot be simply represented by a constant trend. One may wonder if adjusting a trend on time series of mass variation makes physical sense for such short time spans (i.e., a few years). Instead of considering a constant rate of ice mass loss, we propose integrating numerically the total ice mass variations versus time, to establish a more realistic mass balance of the melting GrIS, which remains completely time-dependent at the multi-year time scale.

Figure 4 shows trend maps of the GrIS estimated from the Gaussian and STL filtered solutions for two different time spans. It can be shown that the linearly adjusted trends also depend geographically upon the chosen time span. Considering a short period (2003-2007) makes small positive trends appear in the north east of Greenland, whereas 
considering the complete time span (2003-2010) does not reveal any positive anomalies. For the period 2003-2007, the northern patterns of the STL-decomposed mass trend remain consistent with the ones described by Zwally et al. (2011) using ICESat data.

\subsection{Regional mass balances}

Time series of the mass balance for different Greenland ice-field basins were computed using the geographical boundaries from Luthcke et al. (2006). They are presented on Fig. 5. If the whole GrIS exhibits a clear mass depletion over 2003-2010, the situation is more contrasted at regional scale. The highest mass loss occurs in the southeastern part of the continent with an average rate of $-107 \mathrm{Gt} / \mathrm{yr}$ and $-120 \mathrm{Gt} / \mathrm{yr}$ for ICA and Gaussian solutions respectively (Fig. 3c, d, e). In general, mass depletion is larger in coastal regions than inside the continent due to a huge amount of ice lost by coastal glaciers along the south coast.

Our regional estimates remain numerically comparable to the per-basin mascons values found by Luthcke et al. (2006) for the period 2003-2005, where the most significant mass loss occurs in the southeastern regions of Greenland (i.e., -71 Gt/yr). Once again, the difference with our estimates comes from the facts that: (i) the period of time we consider is longer (e.g., non-stationarity of the signals at inter-annual time-scales), and (ii) mascons solutions probably provides a smoother solution as it is based on spatial a priori constraints of a few hundreds of km (Rowlands et al., 2005).

\subsection{Comparison with simulated snow depth}

To explain the interannual variations of the GrIS, comparisons between GRACEderived mass changes and simulated snow depth (SD) were achieved. Assuming that the horizontal displacements are low at the top of the ice fields (and then accelerate progressively down to the coast), and assuming that the mass balance depends only upon vertical mass fluxes (i.e. snow fall), we first computed correlation maps between the monthly mass anomalies from the different GRACE products and the monthly SD from ERA-interim over the period 2003-2010 (Fig. 6). The results for CSR (ICA 400 km), CSR (GAUSS 400 km), GFZ (GAUSS $400 \mathrm{~km}$ ), and JPL (GAUSS $400 \mathrm{~km}$ ) are 
presented on Fig. 6a, b, c, and d respectively. We chose to only present the correlation map for that ICA CSR solution as the results obtained using GFZ and JPL solutions are very similar by construction (Frappart et al., 2010). High correlation coefficients $(>0.7)$ are obtained over northern Greenland for the ICA, and CSR and GFZ Gaussian solutions, except in the northeastern part where ICA products exhibit negative correlation with snow depth. On the contrary, for the JPL Gaussian-filtered solutions high correlations are present only on the northwestern part of Greenland. For the southern part, CSR and JPL Gaussian solutions present medium to high correlation coefficients in the west, and negative correlations in the east, whereas GFZ Gaussian solutions exhibit negative correlations except over a small region in the center where correlations are low (0.3 to 0.4$)$.

The spatial pattern of the correlation between SD and for GRACE solutions is more consistent with other independent data sets for the ICA solutions. For these solutions, the greater correlations are found on the higher altitudes ( $>2000$ or $2500 \mathrm{~m}$ ) where the GrIS is nearly in balance due to small annual cycles and seasonal variations (Luthcke et al., 2006), and negative correlations are found at lower elevations where precipitation is increasingly rainfall rather than snowfall due to a rise of air temperatures (Krabill et al., 2000; Chylek et al., 2004; van den Broeke et al., 2009). In contrast, negative correlations are present mainly on the southwest coast, in the southeast, and in a small region in the northeast of Greenland. The time variations of the GrIS mass anomalies in these regions show that the mass decreases (2003-2008) or is balanced (2008-2010), even when snow depth increases (see basin 3 to 5 in Fig. 7). These regions are covered with large glaciers, such as the Jacobshavn, Kangerlugssuaq and Helheim glaciers. The latter two have experienced an acceleration of their depletion rate in the recent years: acceleration in 2002-2003, deceleration in 2006, and acceleration in 2007 (Howat et al., 2007; Rignot et al., 2008). This spatial pattern is also in good accordance with modeled mass changes and discharge of the GrIS over 20032008 (van den Broeke et al., 2009), the anomalies of mean annual runoff (Hanna et al., 2005), air temperatures (Hanna et al., 2008), and melting days (Mote, 2007; Tedesco et al., 2011) during recent years: high correlations between SD and ICA solutions can be related to increasing mass, negative anomalies of temperatures and melting days, 
and vice versa. This result confirms that the mass balance of the GrIS is dominated by snowfall in regions of high elevation and by glacier discharge in regions of lower elevations.

\subsection{Comparison with Sea Surface Temperature}

The recently observed reduction of both extent and duration of winter sea-ice should cause an increase of snowmelt and glacier discharge due to an advection of warmer water from the ocean (Hanna et al., 2008). These observations coincide with a rapid succession of retreats and advances of the largest outlet glaciers (Luckman et al., 2006; Howat et al., 2007; Joughin et al., 2008; Moon and Joughin, 2008; Rignot et al., 2008) and suggest that Sea Surface Temperature (SST) and deeper ocean temperatures may have a strong impact on glacier dynamics (Hanna et al., 2009), especially when no strong correlation between air temperature and glacier dynamics was observed (Murray et al., 2010).

We focus here on the largest glaciers, present in the south east of Greenland, in the region where snow depth change is not correlated with the mass change observations from GRACE (see Fig. 6 and basin 4 in Fig. 7). The mass variations derived from GRACE in this region were compared with SST along the south east coast of Greenland. Interannual trends of mass anomalies from GRACE and SST from NOAA are presented on Fig. 8 for several glaciers (further abbreviated with G1-G4, see Fig. 1) and locations in the Arctic Ocean (abbreviated with S1-S3). The interannual trends for south east Greenland present a decrease of the mass loss starting in 2006, consistent with the slow down and advance post-2005 of the glaciers' outlets, observed using multispectral and Synthetic Aperture Radar (SAR) images (Howat et al., 2008; Moon and Joughin, 2008; Murray et al., 2010). The mass loss over the 2003-2010 time period is larger for southern glaciers $(-72 \pm 1 \mathrm{~mm} / \mathrm{yr}$ and $-73 \pm 2 \mathrm{~mm} / \mathrm{yr}$ on average for ICA and Gaussian solutions respectively at point G4) than for northern ones ( $-41 \pm 1 \mathrm{~mm} / \mathrm{yr}$ and $-44 \pm 1 \mathrm{~mm} / \mathrm{yr}$ in average for ICA and Gaussian solutions respectively at point G1). These results are in good agreement with estimates of surface mass balance models, which show that the largest variations of winter accumulation and runoff are located in the southeastern parts of Greenland (Murray et al., 2010). 
Comparisons of interannual mass changes and SST in the north show that an increase (respectively a decrease) of SST is followed by an acceleration (respectively a deceleration) of the mass change, whereas a decrease (respectively an increase) of SST in the south is followed by an deceleration (respectively an acceleration) of mass change. Larger correlations are found for northern ocean points. It seems that glacier mass variations are strongly influenced by seasonal northern SST changes (succession of positive and negative temperature events) with a time lag of 120 to 240 days and impact the SST in the south of Greenland, close to Fram Strait. This suggests that warming/cooling phases of coastal oceanic currents can cause dynamic glacier change, as a negative feedback between glaciers and the East Greenland Coastal Current (EGCC) evoked by Murray et al. (2010).

\section{Conclusion}

Our study presents a re-evaluation of the mass balance of the Greenland ice sheet using the Level-2 GRACE solutions over the period October 2002-July 2010 and using two post-processing methods to reduce noise and estimate trends. If our results corroborate what was found previously for shorter time spans, the most recent observations show, for the very first time since the launch of the GRACE mission, a decrease in mass loss of the GrIS for all the considered sources (UTCSR, GFZ, and JPL) and several filtering methods (Gaussian and Gaussian + ICA for averaging radii of 300, 400, and $500 \mathrm{~km}$ ). The methodology, based on the combination of a Gaussian filter and an ICA approaches, reduces contamination by the spurious north-south stripes, and provides mass change rates more consistent with each other than classical filtering techniques. The decrease of GrIS ice mass is clearly not constant in time, but contains interannual variability suggesting that the ice mass melting is a transitional complex phenomenon. In terms of methodology, we therefore remain very critical about simply fitting a simple straight line to a set of points that contains different levels of noise. There are important implications in understanding the causes of an observed continuous sea level change. If the mass contribution of the ice sheets melting to sea level is not constant

at interannual time scales, and less than previously expected, this means a larger steric 
(i.e., thermal) contribution in response of global warming. We also attempted to investigate these long-term variations by studying correlations with climate variables. The GrIS mass balance is governed inside the continent by the snow accumulation and by the dynamics of glaciers in the coastal regions. The increase in snowfall since winter 2008-2009 in the south and since 2009-2010 in the north, and also a deceleration of the glacier discharge since 2008 reported in several studies using independent data, are responsible for the decrease in mass loss of Greenland. The mass changes of the glaciers present in the southwest of Greenland were found to be anticorrelated with the SST of the Denmark strait. This confirms the assumption of Murray et al. (2010) that glacier dynamics of southeast Greenland are controlled by the oceanic currents. Unfortunately, the spatial resolution of the GRACE data $(\sim 333 \mathrm{~km}$ for harmonic coefficients expanded up to degree 60) is insufficient to resolve fjord scales.

Acknowledgements. This work was done by I. Bergmann during a three-month internship at CNES/GRGS, Observatoire Midi-Pyrénées, Toulouse, France in 2010. The authors wish to thank Lucia Seoane (GET, OMP) for preprocessing the available years of GRACE and Pascal Gegout (GET, OMP) for helping us with the processing of the ECMWF data, as well as A. Cazenave (LEGOS, OMP) for fruitful discussions.

Allison, I., Alley, R.B., Fricker, H.A., Thomas, R.H., Warner, R., 2009. Ice sheet mass balance and sea level. Antarct. Sci. 21, 413-426.

Baur, O., Kuhn, M., Featherstone, W.E., 2009. GRACE-derived ice-mass variations over Greenland by accounting for leakage effects. J. Geophys. Res. Vol. 114, B06407.

Bettadpur, S., 2007. GRACE 327-734 (CSR-GR-03-01) Gravity Recovery and Climate Experiment Level-2 Gravity Field Product User Handbook. Technical Report. Center for Space Research, The University of Texas in Austin.

Box, J.E., Cohen, A.E., 2006. Upper-air temperatures around Greenland: 1964-2005. Geophys. Res. Lett. 33, L12706.

van den Broeke, M., Smeets, P., Ettema, J., 2009. Surface layer climate and turbulent exchange in the ablation zone of the west Greenland ice sheet. Int. J. Climatol. Vol. 29, p. 2309-2323.

Chen, J. L., Wilson, C. R., Tapley, B. D., 2006. Satellite gravity measurements confirm accelerated melting of Greenland ice sheet. Science Vol. 313, 1958-1960. 
Chen, J. L., Wilson, C. R., Tapley, B. D., 2011. Interannual variability of Greenland ice losses from satellite gravimetry. J. Geophys. Res. 116, B07406.

Chylek, P., Box, J.E., Lesins, G., 2004. Global warming and the Greenland ice sheet. Climatic Change Vol. 63, p. 201-221.

Cleveland, Robert, B., Cleveland, W.S., McRae, J.E., Terpenning, I., 1990. Stl: A seasonal-trend decomposition procedure based on loess. Journal of Official Statistics Vol. 6, No. 1, p. 3-33.

Comon, P., 1994. Independent Component Analysis, A new concept. Signal Process. Vol. 36, 287-314.

De Lathauwer, L., De Moor, B., Vandewalle, J., 2000. An introduction to independent component analysis. J. Chemometr. Vol. 14, 123-149.

Dee, D. P., Uppala, S. M., Simmons, A. J., Berrisford, P., Poli, P., Kobayashi, S., Andrae, U., Balmaseda, M. A., Balsamo, G., Bauer, P., Bechtold, P., Beljaars, A. C. M., van de Berg, L., Bidlot, J., Bormann, N., Delsol, C., Dragani, R., Fuentes, M., Geer, A. J., Haimberger, L., Healy, S. B., Hersbach, H., Hólm, E. V., Isaksen, L., Kållberg, P., Köhler, M., Matricardi, M., McNally, A. P., Monge-Sanz, B. M., Morcrette, J.-J., Park, B.-K., Peubey, C., de Rosnay, P., Tavolato, C., Thépaut, J.-N., Vitart, F., 2011. The ERA-Interim reanalysis: configuration and performance of the data assimilation system. Q. J. Roy. Meteor. Soc. 137, 553-597.

Dutra, E., Balsamo, G., Viterbo, P., Miranda, P.M.A., Beljaars, A., Schar, C., E., 2010. An improved snow scheme for the ECMWF land surface model: Description and offline validation. J. Hydrometeorol. 11, 899-916.

Frappart, F., Ramillien, G., Leblanc, M., Tweed, S.O., Bonnet, M.P., Maisongrande, P., 2010. Denoising satellite gravity signals by independent component analysis. IEEE Geosci. Remote S. 7, No. 3, 421-425.

Frappart, F., Ramillien, G., Leblanc, M., Tweed, S., Bonnet, M.P., Maisongrande, P., 2011. An independent component analysis approach for filtering continental hydrology in the GRACE gravity data. Remote Sens. Environ. 115, No. 1, 187-204.

Hanna, E., Cappelen, J., Fettweis, X., Huybrechts, P., Lickman, A., Ribergaard, M.H., 2005. Observed and modeled Greenland ice sheet snow accumulation, 1958-2003, and links with regional climate forcing. Hydrol. Process. 23, 7-30. 
Hanna, E., Cappelen, J., Fettweis, X., Huybrechts, P., Lickman, A., Ribergaard, M.H., 2009. Hydrologic response of the Greenland ice sheet: the role of oceanographic warming. Hydrol. Process. Vol. 23, p. 7-30.

Hanna, E., Huybrechts, P., Steffen, K., Cappelen, J., Huff, R., Shuman, C., Irvine-Fynn, T., Wise, S., Griffiths, M., 2008. Increased runoff from melt from the Greenland ice sheet: A response to global warming. J. Climate Vol. 21, p. 331-341.

Howat, I.M., Joughin, I., Fahnestock, M., Smith, B.E., Scambos, T.A., 2008. Synchronous retreat and acceleration of southeast Greenland outlet glaciers 2000-2006: Ice dynamics and coupling to climate. J. Glaciol. 54, 646-660.

Howat, I.M., Joughin, I., Scambos, T.A., 2007. Rapid changes in ice discharge from Greenland outlet glaciers. Science Vol. 315, p. 1559-1561.

Ivins, E. R., James, T. S., 2005. Antarctic glacial isostatic adjustment: a new assessment. Antarctic. Sci. 17, No. 4, 541-553.

Jekeli, C., 1981. Alternative methods to smooth the Earth's gravity field. Technical Report. Departement of Geodetic Science and Surveying, Ohio State University, Columbus, OH.

Joughin, I., Howat, I., Alley, R.B., Ekstrom, G., Fahnestock, M., Moon, T., Nettles, M., Truffer, M., Tsai, V.C., 2008. Ice-front variation and tidewater behavior on Helheim and Kangerdlugssuaq glaciers, Greenland. J. Geophys. Res. 113, F01004.

Krabill, W., Abdalati, W., Frederick, E., Manizade, S., Martin, C., Sonntag, J., Swift, R., Thomas, R., Wright, W., Yingel, J., 2000. Greenland ice sheet: Height-elevation balance and peripheral thinning. Science Vol. 259, No. 5478, p. 428-430.

Luckman, A., Murray, T., de Lange, R., Hanna, E., 2006. Rapid and synchronous ice-dynamic changes in east Greenland. Geophys. Res. Lett. 33, L03503.

Luthcke, S.B., Zwally, H.J., Abdalati, W., Rowlands, D.D., Ray, R.D., Nerem, R.S., Lemoine, F.G., McCarthy, J.J., Chinn, D.S., 2006. Recent Greenland ice mass loss by drainage system from satellite gravity observations. Science Vol. 314, p. 1286-1289.

Moon, T., Joughin, I., 2008. Changes in ice front position on Greenland's outlet glaciers from 1992 to 2007. J. Geophys. Res. 113, F02022. 
Mote, T.L., 2007. Greenland surface melt trends 1973-2007: Evidence of a large increase in 2007. Geophys. Res. Lett. Vol. 34, L22507.

Murray, T., Scharrer, K., James, T.D., Dye, S.R., Hanna, E., Booth, A.D., Selmes, N., Lickman, A., Hughes, A.L.C., Cook, S., Huybrechts, P., 2010. Ocean regulation hypothesis for glacier dynamics in southeast Greenland and implications for ice sheet mass changes. J. Geophys. Res. Vol. 115, F03026.

Paulson, A., Zhong, S., Wahr, J., 2007. Inference of mantle vicosity from GRACE and relative sea level data. Geophys. J. Int. 171, 497-5009.

Peltier, W.R., 2004. Global glacial isostasy and the surface of the ice-age earth: The ICE-5G (VM2) Model and GRACE. Annu. Rev. Earth Pl. Sc. 32, 111-149.

Ramillien, G., Famiglietti, J.S., Wahr, J., 2008. Detection of continental hydrology and glaciology signals from GRACE: A review. Surv. Geophys. Vol. 29, p. 361-374.

Ramillien, G., Lombard, A., Cazenave, A., Ivins, E.R., Llubed, M., Remy, F., Biancale, R., 2006. Interannual variations of the mass balance of the Antarctica and Greenland ice sheets from GRACE. Global Planet. Change Vol. 53, p. 198-208.

Reynolds, R.W., Smith, T.M., 1994. Improved global sea surface temperature analyses using optimum interpolation. J. Climate 7, 929-948.

Rignot, E., Box, J.E., Burgess, E., Hanna, E., 2008. Mass balance of the Greenland ice sheet from 1958-2007. Geophys. Res. Lett. Vol. 35, L20502.

Rignot, E., Velicogna, I., van den Broeke, M. R., Monaghan, A., Lenaerts, J., 2011. Acceleration of the contribution of the Greenland and Antarctic ice sheets to sea level rise. Geophys. Res. Lett. 38, L05503.

Rowlands, D.D., Luthcke, S.B., Klosko, S.M., Lemoine, F.G.R., Chinn, D.S., McCarthy, J.J., Cox, C.M., Anderson, O.B., 2005. Resolving mass flux at high spatial and temporal resolution using GRACE intersatellite measurements. Geophys. Res. Lett. 32, L04310.

Schmidt, R., Flechtner, F., Meyer, U., Neumayer, K.H., Dahle, Ch., K.R., Kusche, J., 2008. Hydrological signals observed by the GRACE satellites. Surv. Geophys. 29, 319-334. 
Sella, Giovanni F., Stein, Seth, Dixon, Timothy H., Craymer, Michael, James, Thomas S., Mazzotti, Stephane, Dokka, Roy K., 2007. Observation of glacial isostatic adjustment in "stable" North America with GPS. Geophys. Res. Lett. 34, L02306.

Swenson, S., Wahr, J., 2002. Methods for inferring regional surface-mass anomalies from Gravity Recovery And Climate Experiment (GRACE) measurements of time-variable gravity. J. Geophys. Res. 107, No. B9, 2193.

Tapley, B.D., Bettadpur, S., Watkins, M., Reigber, C., 2004. The Gravity Recovery And Climate Experiment: Mission overview and early results. Geophys. Res. Lett. 31, L09607.

Tedesco, M., Fettweis, X., van den Broeke, M., van de Wal, R.S.W., Smeets, C., van de Berg, W.J., Serreze, M., Box, J.E., 2011. The role of albedo and accumulation in the 2010 melting record in Greenland. Environ. Res. Lett. 6, 014005.

Velicogna, I., Wahr, J., 2005. Greenland mass balance from GRACE. Geophys. Res. Lett. Vol. 32, L18505.

Velicogna, I., Wahr, J., 2005. Acceleration of Greenland ice mass loss in spring 2004. Nature Vol. 443, 329-331.

Velicogna, I., 2009. Increasing rates of ice mass loss from the Greenland and Antarctic ice sheets revealed by GRACE. Geophys. Res. Lett. Vol. 36, L19503.

Wahr, J., Molenaar, M., Bryan, F., 1998. Time variability of the earth's gravity field: Hydrological and oceanic effects and their possible detection using GRACE. J. Geophys. Res. 103, B3, 30205-30229.

Wouters, B., Chambers, D., Schrama, E.J.O., 2008. GRACE observes small-scale mass loss in Greenland. Geophys. Res. Lett. Vol. 35, L20501.

Zwally, H. Jay, Li, Jun, Brenner, Anita C., Beckley, Matthew, Cornejo, Helen G., Dimarzio, John, Giovinetto, Mario B., Neumann, Thomas A., Robbins, John, Saba, Jack L., Yi, Donghui, Wang, Weili, 2011. Greenland ice sheet mass balance: distribution of increased mass loss with climate warming; 2003-07 versus 1992-2002. J. Glaciol. Vol. 57, 88-102. 
566 6. Tables 
Table 1: Summary of the GRACE-derived mass balance of Greenland

\begin{tabular}{lccc}
\hline & Data set & Time span & Mass loss [Gt/yr] \\
\hline $\begin{array}{l}\text { Velicogna and Wahr } \\
\text { (2005) }\end{array}$ & CSR (RL01) & $04 / 2004-07 / 2004$ & $-41 \pm 14$ \\
$\begin{array}{l}\text { Chen et al. (2006) } \\
\text { Velicogna and Wahr }\end{array}$ & CSR (RL01) & $04 / 2002-11 / 2005$ & $-120 \pm 6$ \\
(2006) & CSR (RL01) & $04 / 2002-04 / 2006$ & $-120 \pm 6$ \\
Luthcke et al. (2006) & mascons & $07 / 2002-07 / 2005$ & $-101 \pm 16$ \\
$\begin{array}{l}\text { Ramillien et al. } \\
\text { (2006) }\end{array}$ & CNES/GRGS (RL01) & $07 / 2003-03 / 2005$ & $-109 \pm 9$ \\
Wouters et al. (2008) & CSR (RL04) & $02 / 2003-01 / 2008$ & $-179 \pm 25$ \\
Baur et al. (2009) & CSR (RL04) & $08 / 2002-07 / 2008$ & $-222 \pm 13$ \\
& GFZ (RL04) & $08 / 2002-07 / 2008$ & $-178 \pm 22$ \\
Velicogna (2009) & JPL & $08 / 2002-07 / 2008$ & $-88 \pm 21$ \\
Chen et al. (2011) & CSR (RL04) & $04 / 2002-02 / 2009$ & $-230 \pm 33$ \\
& CSR (RL04) & $04 / 2002-11 / 2009$ & $-219 \pm 38$ \\
this study & & & \\
& CSR (ICA-400km+STL) & $04 / 2002-07 / 2010$ & $-66 \pm 1$ \\
& CSR (GAUSS-400km + STL) & $04 / 2002-07 / 2010$ & $-92 \pm 1$ \\
& GFZ (ICA-400km + STL) & $04 / 2002-07 / 2010$ & $-63 \pm 1$ \\
& GFZ (GAUSS-400km + STL) & $04 / 2002-07 / 2010$ & $-81 \pm 1$ \\
& JPL (ICA-400km + STL) & $04 / 2002-07 / 2010$ & $-51 \pm 1$ \\
& JPL (GAUSS-400km + STL) & $04 / 2002-07 / 2010$ & $-32 \pm 1$ \\
\hline
\end{tabular}




\section{Figure Captions}

Figure 1: Geographical map of the Greenland Ice Sheet (GrIS) which is portioned into 6 mean ice fields according to Luthcke et al. (2006) (a), and the locations of continental (G) and on-sea (S) points used in this study for signals comparison (b).

Figure 2: Time series of water-equivalent mass of GrIS derived from GRACE solutions of different providers (CSR - blue; GFZ - red; JPL - green), and using different types of filtering (Gaussian with a radius of $400 \mathrm{~km}+$ ICA - plain lines; Gaussian with a radius of $400 \mathrm{~km}$ - dotted lines) (top), and the corresponding interannual time series after STL decomposition (bottom).

Figure 3: Histograms of trend estimates using different providers (CSR, GFZ, JPL) and various time spans, considering a simple linear adjustment after no STL decomposition (a), and after STL decomposition (b). Error bars are from analysis of normal equation for a posterior standard deviation on the adjusted linear slope from observation uncertainties. These latter uncertainties were obtained from formal errors on the monthly Stokes coefficients.

Figure 4: Geographical maps of mass trends over the GrIS using GFZ solutions post-processed using Gaussian filtering with a radius of $400 \mathrm{~km}+$ ICA, and corrected from PGR using the Paulson's tuning of the model ICE-5G, over the period 02/2003-12/2007 with no STL decomposition (a), and with STL decomposition (b), and over the period 02/2003-07/2010 with no STL decomposition (c) and with STL decomposition (d).

Figure 5: Interannual mass change time series obtained after STL decomposition from CSR, GFZ, and JPL GRACE solutions for the six mean ice fields (see Fig. 1), and considering different types of post-processing (low-pass Gaussian filtering with a radius of $400 \mathrm{~km}+$ ICA - plain lines; Gaussian filtering with a radius of $400 \mathrm{~km}$ - dotted lines).

Figure 6: Correlation GrIS maps between interannual STL-decomposed time series of GRACEbased mass variations and snow depth changes from ECMWF reanalysis: a) CSR (ICA $400 \mathrm{~km}$ ), b) CSR (Gaussian $400 \mathrm{~km}$ ), c) GFZ (Gaussian $400 \mathrm{~km}$ ), d) JPL (Gaussian $400 \mathrm{~km}$ ).

Figure 7: Interannual trends after STL decomposition of the GRACE-based mass time series (CSR, GFZ, JPL) and snow depth from ECMWF reanalysis and considering different types of 
post-processing (low-pass Gaussian filtering with a radius of $400 \mathrm{~km}+$ ICA - plain lines; Gaus-

601 sian filtering with a radius of $400 \mathrm{~km}$ - dotted lines) for the six ice fields.

602

603 Figure 8: Local comparisons between time series of GRACE-based GrIS mass change and Sea

604 Surface Temperature (SST) from NOAA for different couple of points (see Fig. 1 for the loca605 tions of these points). 
606 8. Figures 

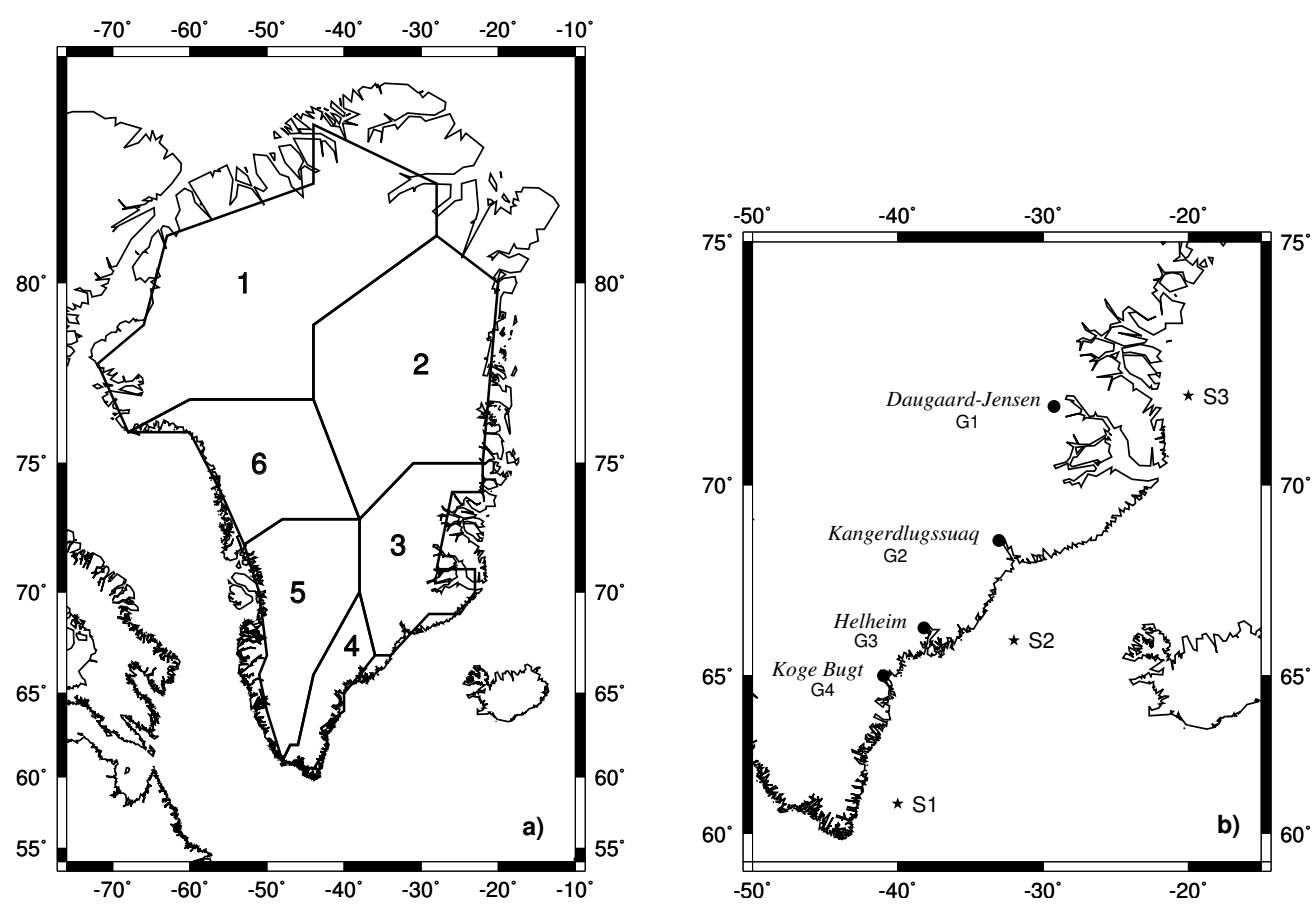

Figure 1 

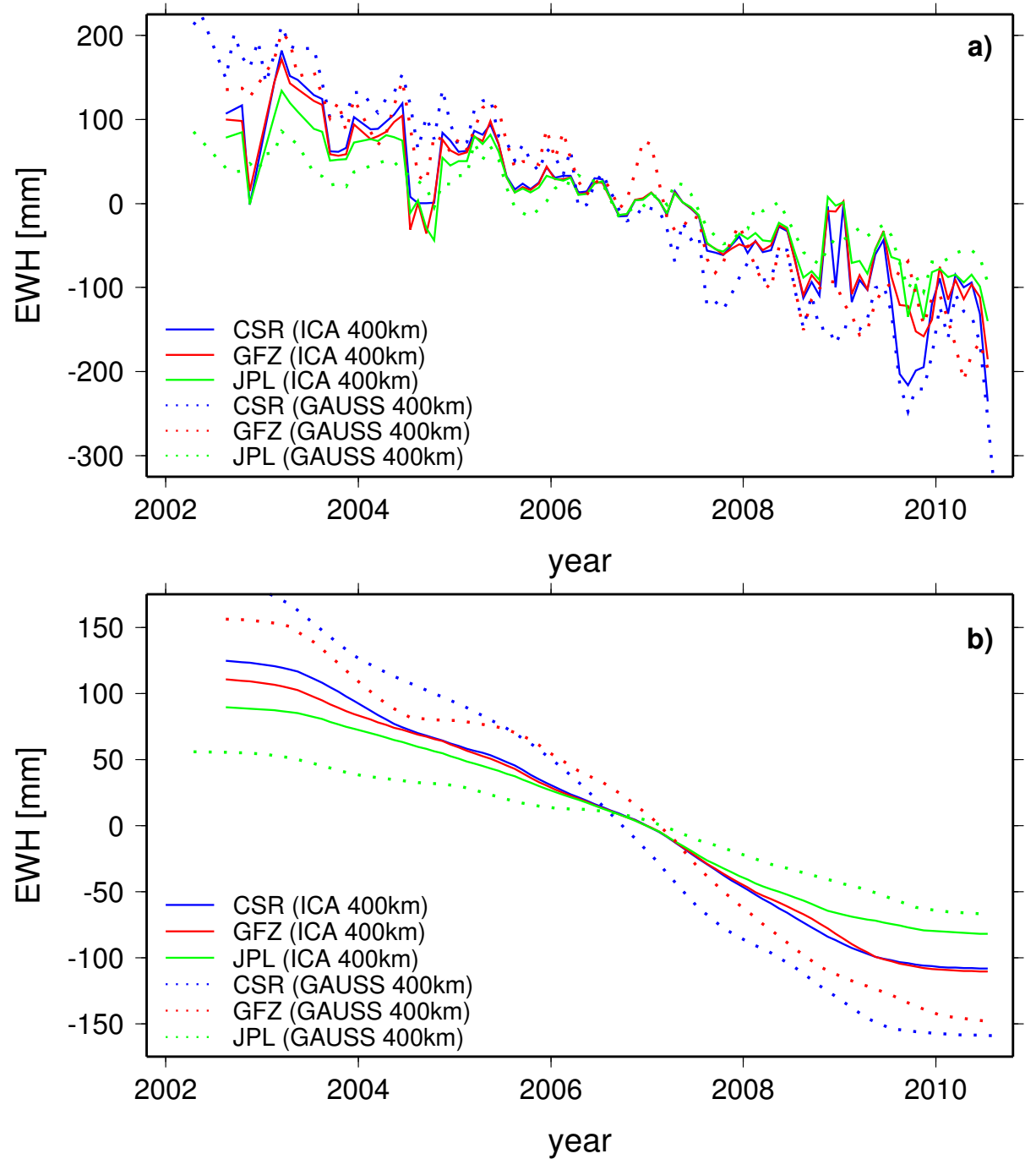

Figure 2 
a)

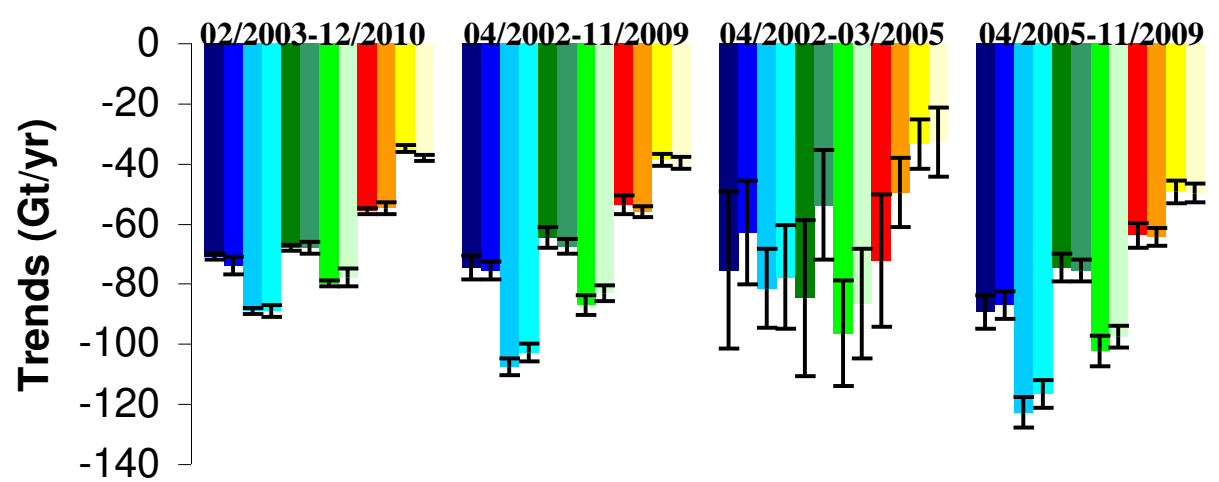

b)

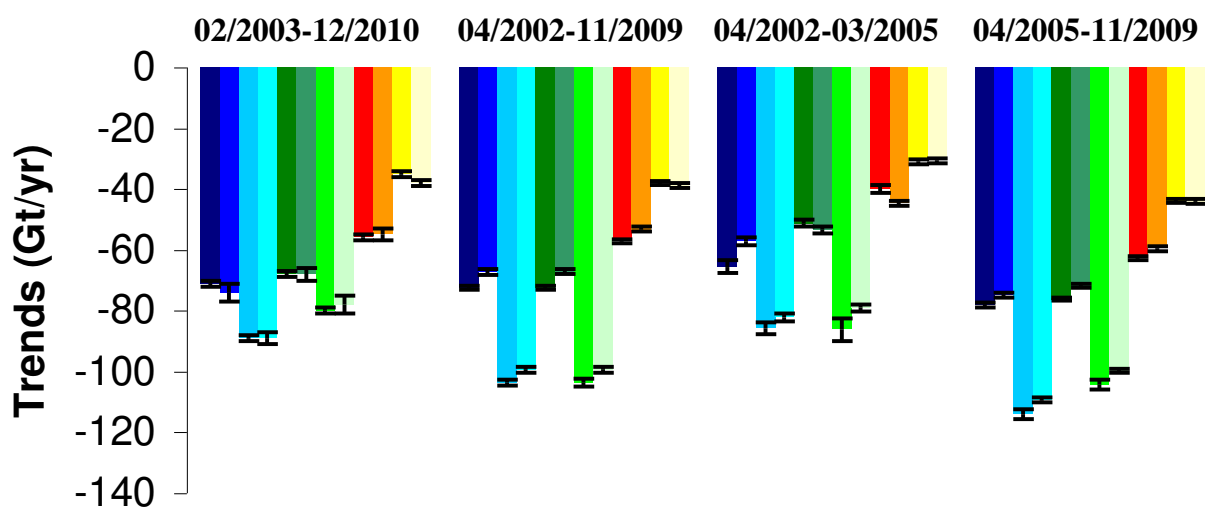

- Gaussian 400 km + ICA - CSR

- Gaussian 500 km + ICA - CSR

Gaussian 400 km - CSR

Gaussian 500 km - CSR

- Gaussian 400 km+ ICA - GFZ

a Gaussian 500 km + ICA - GFZ

- Gaussian 400 km - GFZ

Gaussian 500 km - GFZ

- Gaussian 400 km + ICA - JPL

Gaussian 500 km + ICA - JPL

Gaussian 400 km - JPL

Gaussian 500 km - JPL

Figure 3 

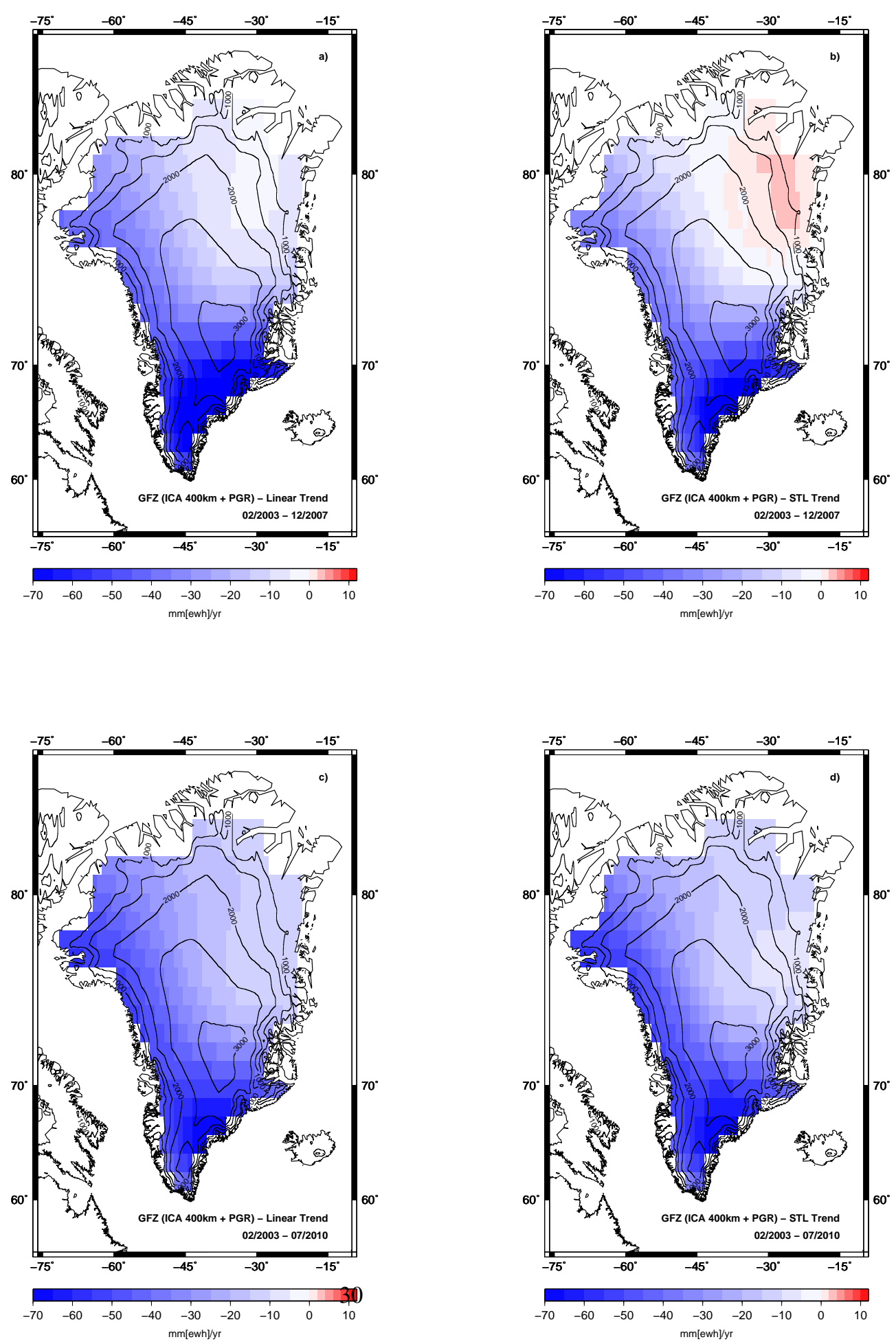

Figure 4 

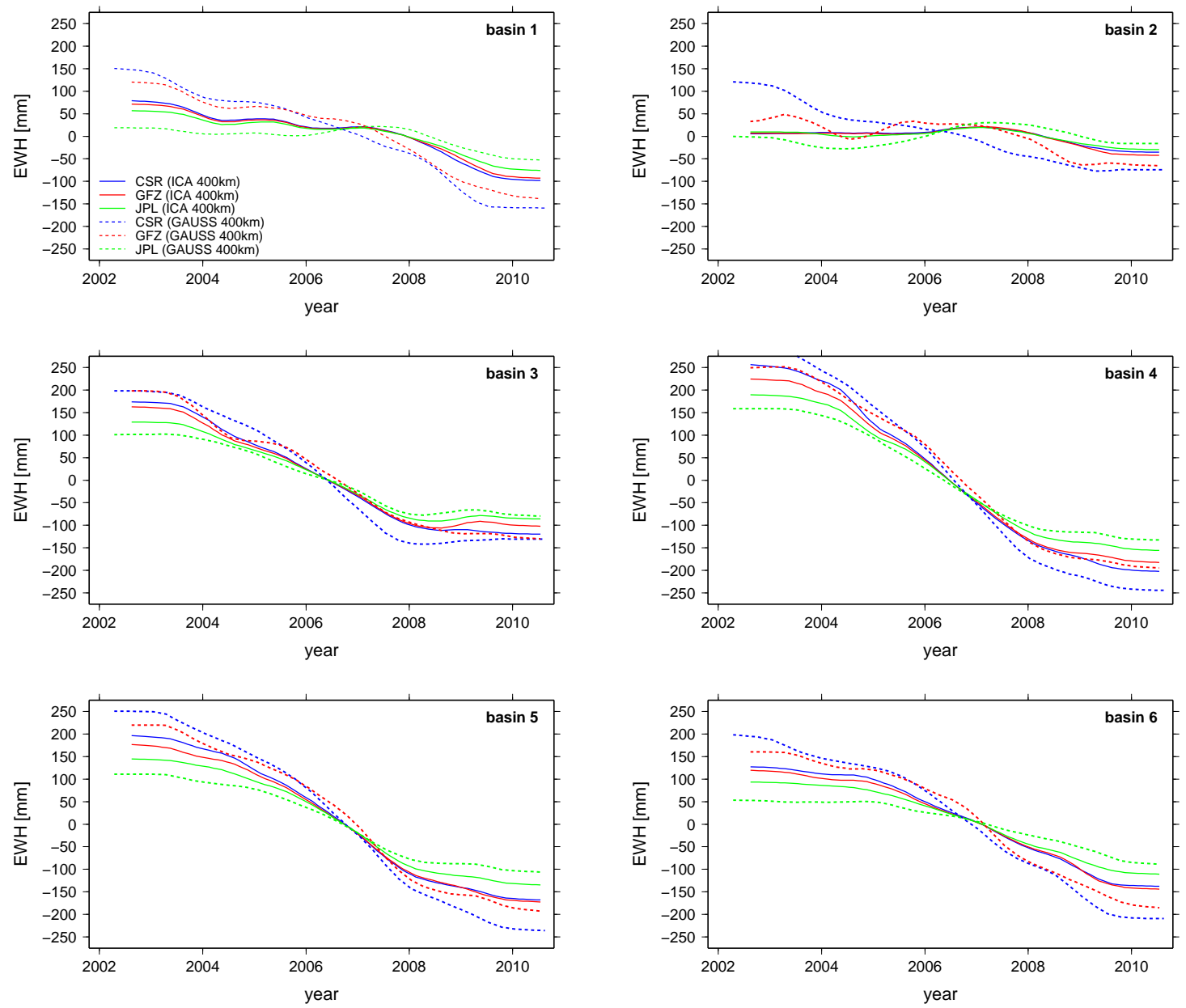

Figure 5 

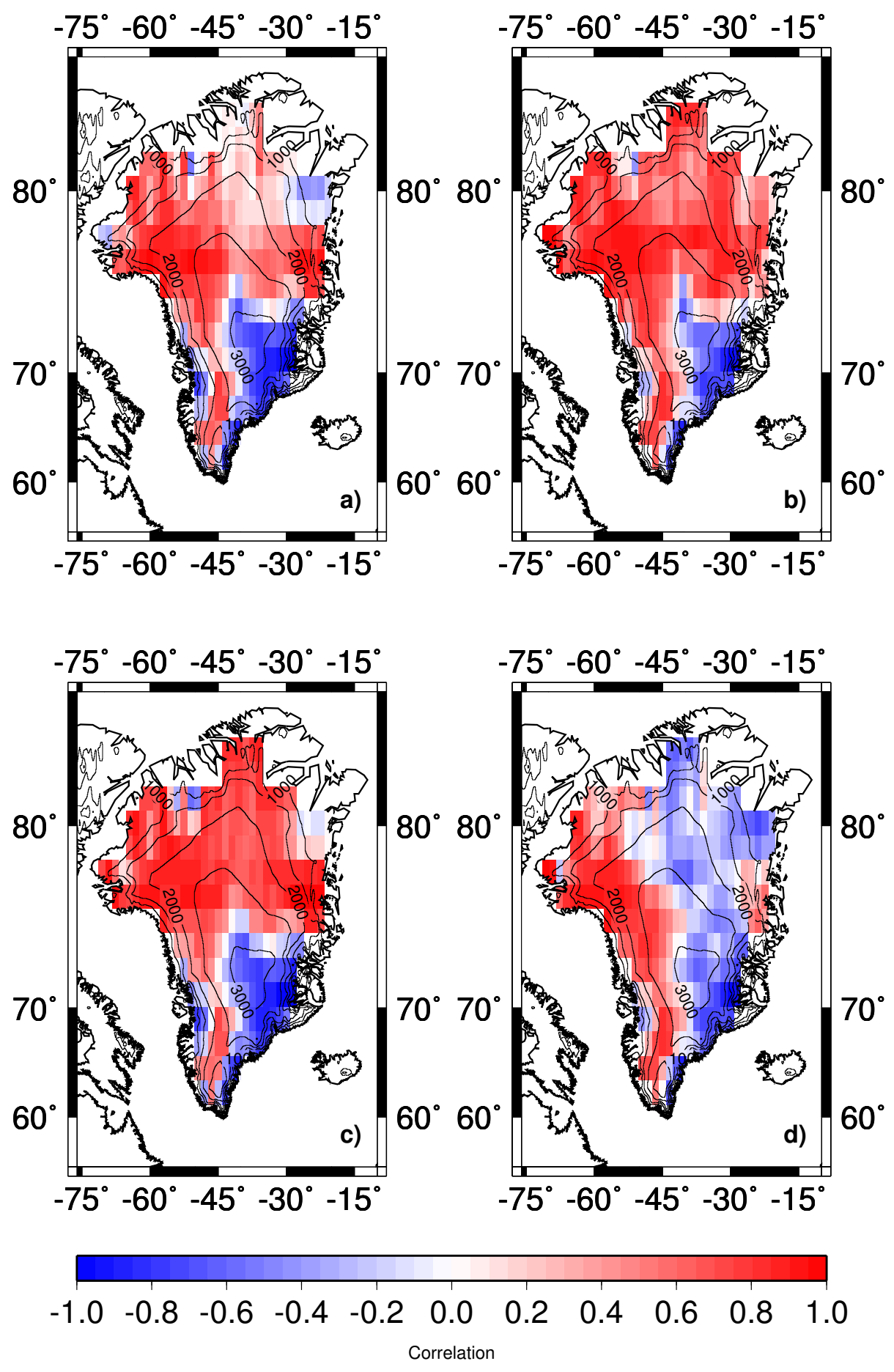

Figure 6 

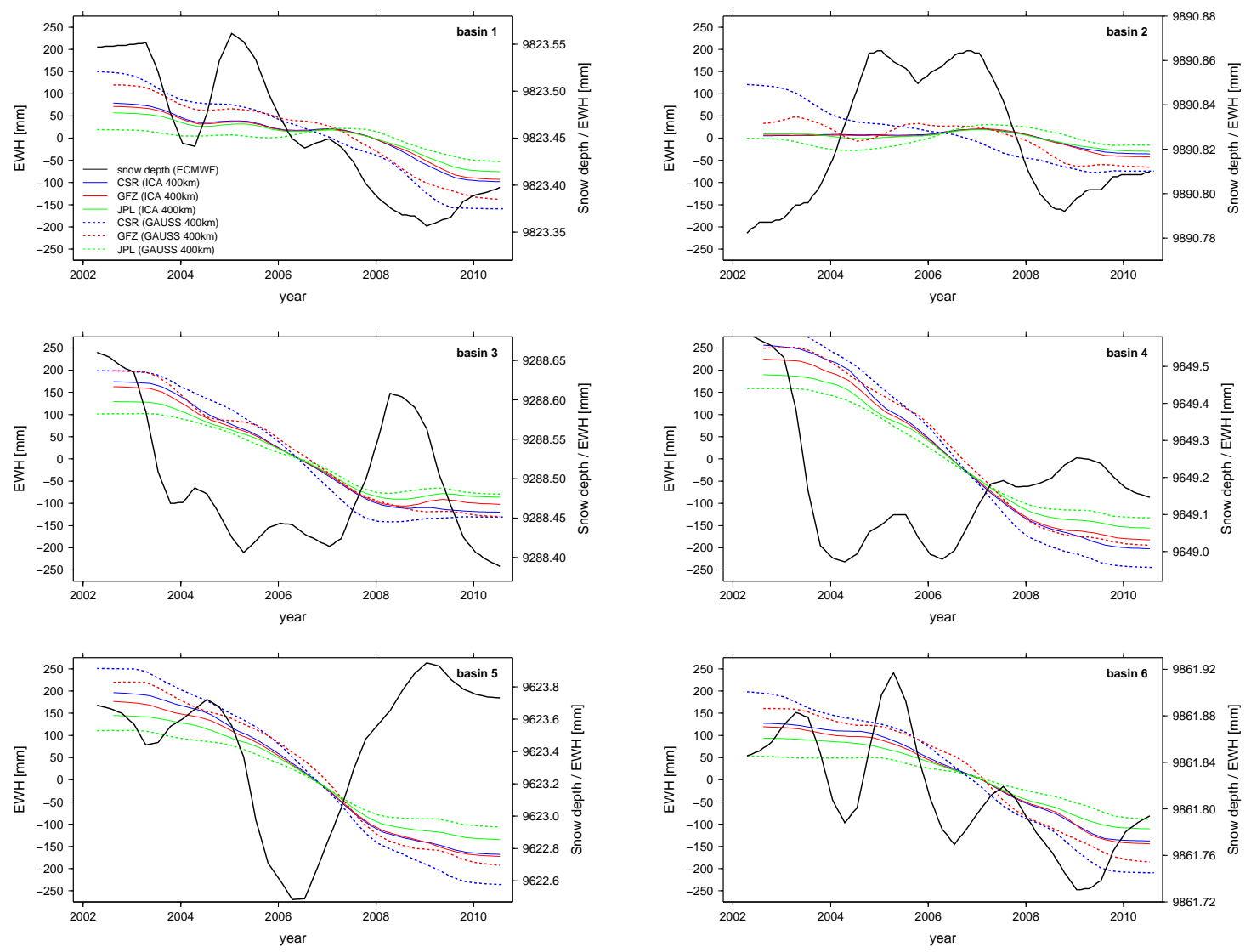

Figure 7 

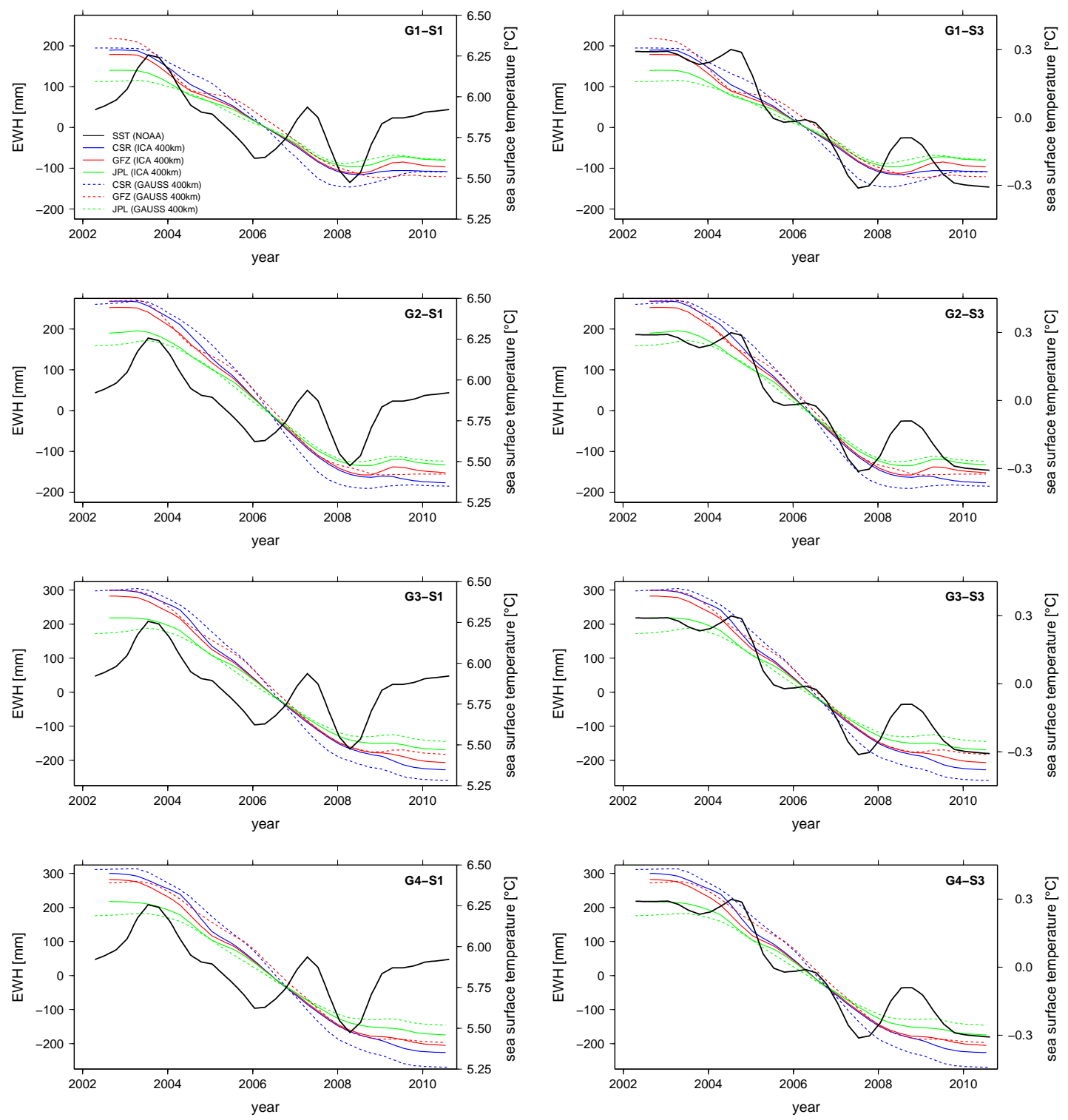

Figure 8 